KREATIF

Jurnal Ilmiah

Prodi Manaiemen Universitas Pamulang
Pamulang ISSN : $2339-0689$, E-ISSN : 2406-8616

J. KREATIF, Vol. 7, No. 2, Desember 2019 (Halaman 19-25)

Tersedia Online di : http://openjournal.unpam.ac.id/index.php/kreatif

\title{
REAKSI PASAR SAHAM PADA PENGUMUMAN CUM EX RIGHT ISSUE PT LIPPO KARAWACI TBK (LPKR) JUNI 2019
}

\author{
Zulfitra, Muliahadi Tumanggor \\ Program Studi Manajemen \\ Dosen Universitas Pamulang \\ dosen00871@unpam.ac.id
}

\begin{abstract}
ABSTRAK
PT Lippo Karawaci Tbk di tahun 2019 melalukan aksi korporasi Right Issue. Aksi ini merupakan fenomena yang menarik bagi investor di pasar modal. Adapun tujuan dari penelitian yaitu untuk membuktikan secara empiris dampak pengumuman Cum Ex Rights Issue terhadap harga saham LPKR di Bursa Efek Indonesia.

Sampel penelitian diambil dari harga saham dengan kode LPKR selama 7 hari sebelum tanggal Cum Right Issue dan 7 hari setelah tanggal Ex Right Issue. Sampel penelitian sebanyak 14 sampel amatan yang diperoleh dari Bursa Efek Indonesia. Penelitian dilakukan menggunakan metode Event Study dengan Dummy Regression Least Square Method.

Hasil penelitian menunjukkan bahwa pengumuman Cum Ex Right Issue berpengaruh signifikan terhadap harga saham.
\end{abstract}

Kata kunci: Cum Ex Right Issue, Harga Saham, Event Study

\section{ABSTRACT}

PT Lippo Karawaci Tbk in 2019 did the Right Issue corporate action. This action is an interesting phenomenon for investors in the capital market. The purpose of the research is to prove empirically the impact of the announcement of the Cum Ex Rights Issue on the price of LPKR shares on the Indonesia Stock Exchange.

The research sample was taken from the share price with the code LPKR for 7 days before the Cum Right Issue date and 7 days after the Ex Right Issue date. The research samples were 14 observational samples obtained from the Indonesia Stock Exchange. The study was conducted using the Event Study method with the Dummy Regression Least Square Method.

The results showed that the announcement of Cum Ex Right Issue had a significant effect on stock prices.

Keywords: Cum Ex Right Issue, Stock Prices, Event Study

\section{PENDAHULUAN}

\section{A. Latar Belakang}

Baru-baru ini, di dalam website-website berita keuangan bisnis sering kita melihat istilah apa yang disebut sebagai right issue. Sehingga timbul pertanyaan, apa yang dimaksud dengan right issue?

Sebuah perusahaan yang telah melakukan penawaran umum saham perdana ke publik, atau sering disebut sebagai (Initial Public Offering), akan memiliki sejumlah besar investor pemegang saham baik dari 
investor perorangan maupun investor institusi. Kemudian setelah proses IPO selesai, perusahaan dapat menerbitkan saham baru lagi sesuai kebutuhan perusahaan.

Investor lama yang sudah memiliki saham perusahaan mendapatkan prioritas dalam memperoleh saham baru sebelum emiten menawarkannya kepada investor baru. Hak yang diberikan kepada investor lama dikenal sebagai right issue. Jika hak-hak ini tidak diambil oleh investor lama, maka saham right issue dapat dibeli oleh investor baru atau biasanya disebut sebagai standby buyer. Harga saham baru yang dikeluarkan selama proses penerbitan disebut sebagai harga wajar. Harga hak ini mungkin lebih rendah, sama dengan atau lebih tinggi dari harga saham saat ini. Tetapi jika investor yang lebih lama ingin mendapat untung lebih besar, sebagian besar harga yang tepat berada di bawah harga pasar. Jadi, investor jangka panjang yang ingin meningkatkan buy-in saham perusahaan memiliki peluang untuk mencapai harga saham yang lebih rendah daripada pasar saham Indonesia. Studi yang dilakukan pada PT Lippo Karawaci Tbk (LPKR). Lippo Karawaci merupakan perusahaan go publik yang bergerak di bidang properti terdiversifikasi, yang merupakan perusahaan property terbesar di Indonesia berdasar jumlah aset dan pendapatannya. Lippo Karawaci mengembangkan properti residensial juga komersial, rumah sakit serta kawasan industri ringan di 35 kota di Indonesia, terutama di dalam dan sekitar lima kota besar utama di Indonesia: Jakarta, Medan, Palembang, Makassar dan Manado. Pada Rights Issue di tahun 2019 Setiap 10 (sepuluh) Saham akan menerima 21 (dua puluh satu) Right Issue. Setiap 1 (satu) Rights Issue berhak untuk membeli 1 (satu) Saham baru dengan nilai nominal Rp100 per Saham. Exercise Price akan menjadi Rp 235 (dua ratus tiga puluh lima rupiah).

\section{B. Perumusan Masalah}

Apakah pengumuman Cum Ex Right Issue berpengaruh terhadap harga saham pada PT Lippo Karawaci Tbk (LPKR).

\section{TINJAUAN PUSTAKA}

\section{A. Teori dan Penelitian Terdahulu}

Dalam teori efisiensi pasar oleh Fama (1970) dijelaskan bahwa pengumuman aksi koorporasi perusahaan seperti Right Issue dikategorikan sebagai efisiensi pasar bentuk setengah kuat. Kemudian data historis terdahulu yang dipublikasi dikategorikan sebagai efesiensi pasar bentuk lemah. Selanjutnya informasi yang tidak dipublikasi merupakan efisiensi pasar bentuk kuat. Peneliti mencoba menguji efisiensi pasar bentuk setengah kuat, yaitu informasi yang dipublikasi dalam hal ini adalah pengumuman Right Issue, dimana peneliti mengambil sampel pada PT Lippo Karawaci, Tbk dengan kode saham LPKR.

Beberapa penelitian terdahulu yang mengkaji peristiwa aksi korporasi Right Issue saham diantaranya dijelaskan oleh Catranti (2009), Yusra (2014), Apsari dan Yasa (2017), Sahroni (2018), Sumantika (2018),

Hubungan Right Issue dengan Return Saham dijelaskan dalam penelitian Catranti (2009) pada perusahaan - perusahaan yang terdaftar 
di Bursa Efek Jakarta merger dengan Bursa Efek Surabaya pada periode 2002-2007. Penelitian ini menjelaskan efek waran yang dikombinasikan dengan beberapa Right Issue.. Hasilnya dikategorikan dalam tiga kelompok sampel: (1) sekelompok perusahaan yang Right Issue dengan Waran, (2) sekelompok perusahaan Right Issue tanpa waran, dan (3) sekelompok perusahaan yang Right Issue di antara2001-2006.

Selanjutnya Yusra (2014) menjelaskan hubungan abnormal return dan perdagangan volume aktivitas sebelum dan sesudah pengumuman rights issue, pada 33 perusahaan yang terdaftar di Bursa Efek Indonesia dari 2005 hingga 2009. Hasil penelitian Yusra (2014) menunjukkan bahwa tidak ada perbedaan yang signifikan dalam periode pengamatan pengembalian abnormal 5 hari, 15 hari, 60 hari, 90 hari, 180 hari sebelumnya dan setelah pengumuman Right Issue dalam kelompok kabar baik dan kabar buruk. Sementara volume aktivitas perdagangan, perbedaan aktivitas volume perdagangan signifikan pada periode 5 hari sebelum pengumuman Right Issue setelah kelompok berita buruk

Apsari dan Yasa (2017) juga mengkaji reaksi pasar terhadap pengumuman Right Issue dan mengetahui adanya abnormal return atau tidak disekitar periode pengumuman right issue pada 73 perusahaan go public dan 90 pengumuman aksi korporasi right issue pada tahun amatan 2011-2015. Apsari dan Yusra (2017) menyimpulkan bahwa pada hari ketiga sebelum Right Issue diumumkan terdapat reaksi pasar yang negative. Kemudian pada saat right issue diumumkan tidak terdapat reaksi pasar. Selanjutnya reaksi pasar yang positif terjadi pada hari pertama dan keempat setelah pengumuman right issue.

Selanjutnya Sahroni (2018) adanya hubungan pengumuman Cum Right Issue dan Ex Right Issue dengan harga saham, studi kasus pada saham CASA (PT. Capital Financial Indonesia, Tbk) di Bursa Efek Indonesia. Sahroni (2018) menggunakan 80 sampel pengamatan saham CASA untuk diuji. Pengamatannya dibagi menjadi dua yaitu 40 pengamatan sebelum Right Issue diumumkan dan 40 pengamatan setelah Right Issue diumumkan. Lebih tepatnya mulai tanggal 6 Desember2017 sampai 2 Februari 2018. Sahroni (2018) menyimpulkan bahwa Pengumuman Cum Ex Right Issue mempunyai pengaruh sangat signifikan pada harga saham CASA.

Selanjutnya Sumantika (2018) menguji bagaimana pasar saham bereaksi terkait dengan pengumuman right issue pada 79 saham di mana 63 sampel digunakan untuk tes pertama dan 62 sampel untuk tes kedua. Hasil penelitian Sumantika (2018) menunjukkan bahwa pengumuman right issue menghasilkan perubahan return positif dan signifikan sebesar $1,32 \%$ dibandingkan dengan periode sebelumnya $0,62 \%$ di mana nilai p-paired sample t-test kurang dari 0,05 . Sementara menguji reaksi pasar terkait dengan ex-date menunjukkan bahwa tidak ada penurunan harga saham yang signifikan dan sebaliknya pasar bereaksi positif walaupun tidak signifikan dengan nilai p lebih dari 0,05. Selanjutnya, Dari 62 sampel, hanya ada 13 saham yang mengalami penurunan harga saham saat ex-date. 


\section{B. Hipotesis Penelitian}

Berdasarkan kajian teori efisiensi pasar dan beberapa penelitian event study terdahulu maka peneliti merumuskan hipotesis penelitian yaitu terdapat pengaruh pengumuman Cum Ex Right Issue terhadap harga saham PT Lippo Karawaci Tbk (LPKR).

\section{METODE PENELITIAN}

Metode dalam penelitian menggunakan Event Study dengan analisis Dummy Regression Least Square Method. Pengolahan data menggunakan Eviews 9 untuk membuktikan secara empiris adanya pengaruh pengumuman Cum Ex Right Issue terhadap harga saham PT Lippo Karawaci Tbk (LPKR)..

Sumber data yang dipergunakan dalam penelitian diperoleh dari website www.duniainvestasi.com dan website Bursa Efek Indonesia. Variable endogen penelitian yaitu harga saham, sedangkan variable eksogen penelitian yaitu Dummy Variable, dimana D1 $=0$, yaitu pengambilan sampel 7 hari pengamatan saat dan sebelum pengumuman Cum Right Issue 21 Juni 2019 di pasar regular dan pasar negosiasi Bursa Efek Indonesia. Kemudian D2 $=1$, pengambilan sample 7 hari pengamatan saat setelah pengumuman Ex Right Issue 24 Juni 2019 di pasar regular dan pasar negosiasi Bursa Efek Indonesia.

\section{HASIL DAN PEMBAHASAN}

Data hasil penelitian yang diperoleh dari Bursa Efek Indonesia untuk 14 hari pengamatan saat sebelum dan setelah pengumuman Cum Ex Right Issue 21 dan 24 Juni 2019 di pasar regular dan pasar negosiasi Bursa Efek Indonesia., adalah sebagai berikut:

Tabel

\section{Data Penelitian}

\begin{tabular}{|r|r|r|}
\hline No. & Dummy & Price \\
\hline 1 & 0 & 308.00 \\
\hline 2 & 0 & 308.00 \\
\hline 3 & 0 & 308.00 \\
\hline 4 & 0 & 314.00 \\
\hline 5 & 0 & 318.00 \\
\hline 6 & 0 & 324.00 \\
\hline 7 & 0 & 338.00 \\
\hline 8 & 1 & 290.00 \\
\hline 9 & 1 & 280.00 \\
\hline 10 & 1 & 280.00 \\
\hline 11 & 1 & 270.00 \\
\hline 12 & 1 & 264.00 \\
\hline 13 & 1 & 272.00 \\
\hline 14 & 1 & 274.00 \\
\hline peneltian & yang & \\
\hline
\end{tabular}

Data hasil peneltian yang diambil dari website www.duniainvestasi.com dan website Bursa Efek Indonesia www.idx.co.id kemudian dikumpulkan lalu diolah dengan menggunakan Software Eviews 
9. Metode yang digunakan dalam penelitian adalah Dummy Regression Least Square Method.

Variable endogen penelitian yaitu harga saham, sedangkan variable eksogen penelitian yaitu Dummy Variable, dimana D1 $=0$, yaitu pengambilan sampel 7 hari pengamatan saat dan sebelum pengumuman Cum Right Issue 21 Juni 2019 di pasar regular dan pasar negosiasi Bursa Efek Indonesia. Kemudian D2 $=1$, adalah pengambilan sample 7 hari pengamatan saat setelah pengumuman Ex Right Issue 24 Juni 2019 di pasar regular dan pasar negosiasi Bursa Efek Indonesia

Hasil pengolahan data dengan Eviews 9 disajikan sebagai berikut :

Dependent Variable: PRICE

Method: Least Squares

Date: 10/20/19 Time: 15:26

Sample: 114

Included observations: 14

\begin{tabular}{|c|c|c|}
\hline Variable & $\begin{array}{l}\text { Coeffici } \\
\text { ent Std. Error Statistic }\end{array}$ & Prob. \\
\hline \multirow{3}{*}{$\mathrm{C}$} & 316.857 & \\
\hline & $\begin{array}{l}13.732556 \\
-\end{array}$ & 0.0000 \\
\hline & 41.1428 & \\
\hline DUMMY & 65.278631 & 0.0000 \\
\hline & \multirow{2}{*}{$\begin{array}{l}0.83505 \text { Mean dependen } \\
\text { 2var }\end{array}$} & 296.28 \\
\hline R-squared & & 57 \\
\hline $\begin{array}{l}\text { Adjusted R- } \\
\text { squared }\end{array}$ & $\begin{array}{c}0.82130 \text { S.D. dependent } \\
\text { 6var }\end{array}$ & $\begin{array}{r}23.361 \\
47\end{array}$ \\
\hline S.E. of & \multirow{2}{*}{$\begin{array}{c}9.87541 \text { Akaike info } \\
\text { 4criterion }\end{array}$} & 7.5495 \\
\hline regression & & 37 \\
\hline Sum squared & 1170.28 Schwarz & 7.6408 \\
\hline resid & 6criterion & 31 \\
\hline \multirow{3}{*}{ Log likelihood } & 50.8467 Hannan-Quinn & 7.5410 \\
\hline & 6 criter. & \\
\hline & 60.7500 Durbin-Watson & 0.5426 \\
\hline \multirow[t]{2}{*}{ F-statistic } & 0stat & 20 \\
\hline & 0.00000 & \\
\hline Prob(F-statistic) & 5 & \\
\hline
\end{tabular}

Dummy Regression Least Square Model disajikan sebagai berikut :

Estimation Command:

LS PRICE C DUMMY

Estimation Equation:

PRICE $=\mathrm{C}(1)+\mathrm{C}(2) * \mathrm{DUMMY}$

Substituted Coefficients:

PRICE $=316.857142857-41.1428571429 *$ DUMMY 
Berdasarkan hasil penelitian dapat kita lihat bahwa pada saat dan setelah pengumuman Es Right Issue terjadi penurunan harga saham yang signifikan. Dalam Right Issue terdapat 2 tanggal penting yaitu tanggal Cum dan tanggal Ex. Tanggal Cum (atau cum date) merupakan tanggal terakhir dimana seorang investor masih dapat meregistrasikan saham yang dimilikinya (saham lama) untuk mendapatkan hak corporate action (berupa saham Right Issue). Sedangkan tanggal Ex (Ex date) yaitu tanggal dimana investor sudah tidak lagi memiliki hak akan suatu aksi korporasi dalam hal ini Right Issue. Yang berarti jika membeli saham pada tanggal ex-right, maka akan memperoleh saham yang sudah tidak memiliki hak atas right issue. Oleh karena itu pada tanggal Ex (Ex date) di pasar saham biasa, harga saham biasa cenderung turun, karena terjadinya aksi jual di tanggal tersebut. Sedangkan di pasar saham Right Issue, harga saham Right Issue cenderung meningkat atau terjadi aksi beli. Sehingga apa bila disimpulkan, bahwa selama 7 hari pada saat dan sebelum tanggal Cum Right Issue terjadi peningkatan harga saham biasa. Kemudian selama 7 hari pada saat dan setelah tanggal Ex Right Issue terjadi penurunan harga saham biasa. Peningkatan dan penurunan ini terjadi secara signfikan berdasarkan pengujian dengan metode Dummy Regression Least Square Method.

Untuk lebih jelasnya dapat dilihat pada grafik candle stick harga saham LPKR sebagai berikut :

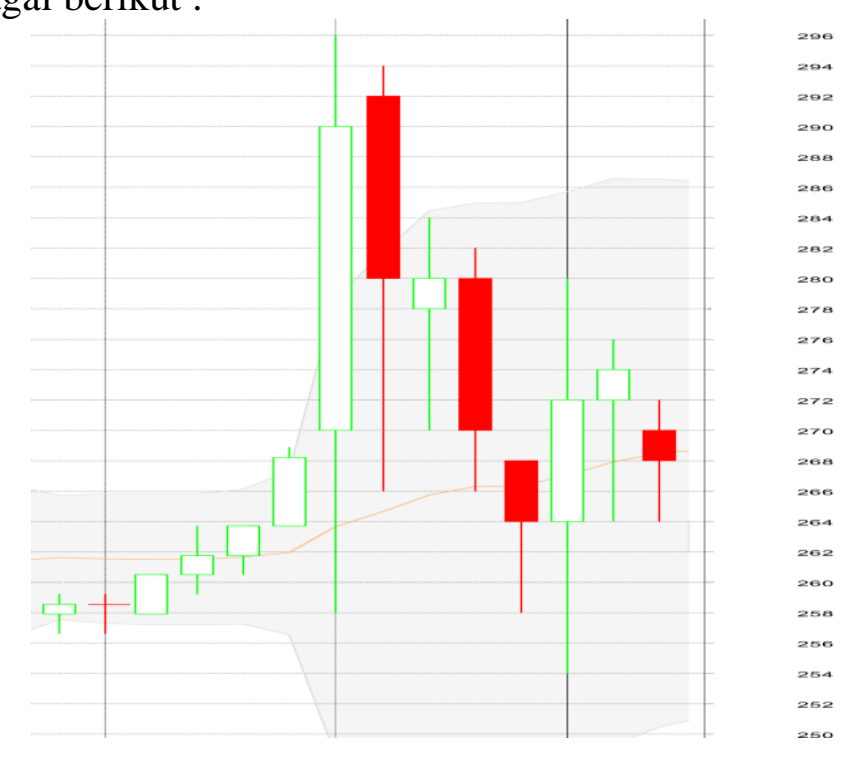

\section{KESIMPULAN DAN SARAN}

\section{A. Kesimpulan}

Berdasarkan hasil dari penelitian maka dapat disimpulkan bahwa pengumuman Cum Ex Right Issue berpengaruh signifikan terhadap harga saham PT Lippo Karawaci Tbk (LPKR).

\section{B. Saran}

Investor perlu mencermati terjadinya aksi korporasi Right Issue agar dapat menikmati keuntungan baik pada peningkatan saham biasa maupun peningkatan pada saham Right Issue. Selain itu juga investor agar mengantisipasi penurunan harga saham biasa pada tanggal Ex Right Issue. Saran bagi penelitian selanjutnya yaitu perlu adanya kajian yang lebih mendalam, karena selain pengaruh dari pengumuman Cum Ex 
Right Issue, masih ada faktor-faktor lain yang dapat mempengaruhi harga saham, khususnya pada studi saham di PT Lippo Karawaci, Tbk (LPKR).

\section{DAFTAR PUSTAKA}

Apsari, Ida Ayu Wiasti Paramita., Yasa, Gerianta Wirawan. (2017). Analisis Reaksi Pasar Terhadap Pengumuman Right Issue Pada Perusahaan Go Public Yang Tercatat Di BEI. E-Jurnal Akuntansi Universitas Udayana Vol.18.2. Februari (2017): 1343-1368.

Bambang Juanda, Junaidi. 2012. Ekonometrika Deret Waktu Teori dan Aplikasi, Penerbit PT. Penerbit IPB Press, Kampus IPB Taman Kencana Bogor.

Bambang Juanda. 2009. Ekonometrika: Pemodelan dan Pendugaan, IPB Press, Bogor.

Catranti, Aski. (2009). Pengaruh Rights Issue terhadap Imbal Hasil Saham dan Volume Perdagangan. Bisnis \& Birokrasi, Jurnal Ilmu Administrasi dan Organisasi, Sept-Des 2009, hlm. 188-203, Volume 16, Nomor 3.

Fama, Eugene F.. (1970) Efficient Capital Markets: A Review of Theory and Empirical Work. The Journal of Finance, Vol. 25, No. 2, Papers and Proceedings of the Twenty-Eighth Annual Meeting of the American Finance Association New York, N.Y. December, 28-30, 1969 (May, 1970), pp. 383-417, Published by: Blackwell Publishing for the American Finance Association.

Gujarati, N. Damodar, dan Porter, C. Dawn. 2010. Basic Econometrics, 5th edition, The McGraw-Hill Companies.

Sahroni (2018). Pengujian Efisiensi Pasar Pada Pengumuman Right Issue Saham CASA PT. Capital Financial Indonesia Tbk. JURNAL SEKURITAS (Saham, Ekonomi, Keuangan dan Investasi) Vol.1, No.4, Juni 2018 Halaman : 16-23.

Sumantika, Ahsan. (2018). Pengumuman Right Issue, Ex-Date \& Perubahan Harga Saham. EFEKTIF, Jurnal Bisnis dan Ekonomi Volume 9, No.2, Desember 2018, 73 - 86

Yusra, Irdha. (2014). Analisis Return Dan Likuiditas Saham Sebelum Dan Sesudah Pengumuman Right Issue Di Bursa Efek Indonesia. Jurnal Riset Manajemen dan Akuntansi Volume 1 - No.2, Oktober 2014. 